\title{
Veri Zarflama Analizi ile Göreli Etkinliklerin Karşılaştırılması: Türkiye'deki İllerin Kültürel Göstergelerine İlişkin Bir Uygulama
}

\author{
Yrd. Doç. Dr. Algin OKURSOY \\ A.D.Ü., Söke İșletme Fakültesi, Yönetim Bilişsim Sistemleri Bölümü, AYDIN \\ Yrd. Doç. Dr. Didem TEZSÜRÜCÜ \\ A.D.Ü., Söke Issletme Fakültesi, Inssan Kaynakları Yönetimi Bölümü, AYDIN
}

\begin{abstract}
$\ddot{O Z Z E T}$
Veri Zarflama Analizi (VZA), doğrusal programlama modeline dayalı parametrik olmayan bir analiz yöntemidir. Benzer girdileri kullanarak, aynı tür çıktıları üreten karar verme birimlerinin (KVB) göreli etkinliklerinin ölçülmesini amaçlamaktadır. VZA, kamudan özel sektöre kadar çok geniş bir uygulama alanına sahiptir. Bu çalı̧̧mada, Türkiye'nin 81 iline ait kültürel göstergeler kullanılarak, illerin kültürel ekonomilerinin VZA ile göreli etkinliklerinin değerlendirilmesi amaçlanmaktadır. Bu kapsamda, Türkiye İstatistik Kurumu'nun (TUIK) yayınladığı kültürel göstergeler içerisinden on tanesi girdi, altı tanesi de çıktı değişkeni olarak VZA'ya dahil edilmiştir. Analiz sonucunda, etkin ve etkin olmayan iller belirlenerek, kültürel ekonomilerinin geliştirilebilmesi için olası iyileştirme önerileri tartışılmıştır.
\end{abstract}

Anahtar Kelimeler: Veri Zarflama Analizi, Kültürel Göstergeler, Kültür Ekonomisi

JEL Sinıflaması: C44, C61, D24

Comparison of the Relative Efficiencies by the Data Envelopment Analysis: An Application in Turkey for the Provinces of Cultural Indicators

ABSTRACT

Data Envelopment Analysis (DEA) is a nonparametric method based on linear programming. DEA aims to measure relative efficiencies of decision making units (DMU) that produces same sort of outputs by using similar inputs. DEA has a wide range of application in the both private and public sector. The purpose of this study is to evaluate relative efficiencies of provinces' cultural economies by cultural indicators of provinces in Turkey. In this context, 10 of the cultural indicators were selected as input variables and six of them were selected as output variables from TUIK data sources. According to result of analysis, effective and non-effective provinces were determined and possible suggestions were discussed to improve local cultural economies.

Key Words: Data Envelopment Analysis, Cultural Indicators, Cultural Economy

JEL Classification: C44, C61, D24

\section{Giriş}

Veri Zarflama Analizi (VZA); etkinlik ölçümünde en çok kullanılan yöntemlerden biridir. Parametrik olmayan bir yöntem olan VZA, herhangi bir üretim fonksiyonunu kullanmak yerine en etkin firmanın girdi ve çıktıları kullanılarak elde edilen eğri üzerindeki noktaları belirlemek için doğrusal programlamayı kullanmaktadır (Fanchon, 2003: 175).

VZA, çok sayıdaki girdiyi çok sayıdaki çıktıya dönüştüren Karar Verme Birimi (KVB) olarak adlandırılan benzer birimlerin performanslarını 
değerlendirmede kullanılan bir yaklaşımdır (Cooper vd., 2011: 1-2). VZA'nın özündeki temel düşünce, kıyaslanabilir KVB'ler içerisinde en iyi olanı belirleyecek ve etkin sınırı oluşturacak bir metodoloji sağlamaktır. Buna ek olarak, metodoloji etkin sinırda olmayan birimlerin etkinlik düzeyini ölçmeye ve etkin olmayan birimlerin kıyaslanabileceği referans birimlerin belirlenmesine olanak sağlamaktadır (Cook ve Seiford, 2009: 1-2).

1978 y1linda Charnes, Cooper ve Rhodes tarafindan literatüre kazandırılan VZA, basit ama aynı zamanda güçlü bir yöntemdir. VZA'nın yaygın kullanımı girdiler ve çıktılar üzerinde öncelik ağırlıkları olmaksızın KVB'lerin göreli etkinliklerini ölçmesinden kaynaklanmaktadır. Günümüzde VZA farklı alanlardaki birçok araştırmacı tarafından eğitim, bankacılık, tarım, bilgi teknolojileri ve bilgi sistemleri, bilgisayar endüstrisi, elektrik santralleri, havayolu taşımacılığı, hisse senedi piyasası ve tedarik zinciri gibi alanlarda yaygın olarak kullanılmaktadır (Kuah vd., 2010: 168).

\section{ETKİNLİK KAVRAMI VE VZA}

Rekabetin yoğun olduğu ortamda, üretim birimlerinin performansının ölçülmesi ve etkinsizlik kaynaklarının belirlenmesi, herhangi bir üretim biriminin performansının iyileştirilmesinde önkoşuldur (Vincova, 2005: 24). Girdilerin, işletmenin belirlediği amaçlar doğrultusunda ne denli etkin ya da yeterli kullanıldığını gösteren bir değerlendirme kriteri olan etkinlik kavramı ve etkinliğin ölçülmesi oldukça önemli hale gelmiştir. Bu nedenle, akademisyenler etkinliğin ölçümünde kullanılan VZA metodolojisi ile ilgili çalışmalara ağırlık vermektedirler.

\section{A. Etkinlik Kavramı}

Literatürde etkinlik kavramının yer alması Koopsman'ın 1951'deki teknik etkinlik kavramını açıkladığı çalışmaya dayanır. Koopsman teknik etkinliği, eş zamanlı olarak diğer çıktıyı azaltmadan (ya da diğer girdiyi arttırmadan) herhangi bir çıktı miktarını arttırmanın (ya da herhangi bir girdi miktarını azaltmanın) teknolojik mümkün olmadığı girdi/çıktı vektörü olarak tanımlamıştır. Debreu (1951) ve daha sonra Farrell (1957), gözlenen çıktıların üretimi ile uyumlu tüm girdilerdeki maksimum radyal azalışın ölçüsü olarak teknik etkinlik kavramını geliştirmişlerdir (Ruggiero ve Bretschneider, 1998: 438).

Farrell (1957), bir işletmenin etkinliğini, eldeki veri girdilerden olabilecek maksimum çıktıyı üretme başarısı olarak tanımlamıştır. Tüm girdi ve çıktıların doğru şekilde ölçülmesi koşuluyla bu kullanımın genel olarak kabul edilebileceğini belirtmiştir. Farrell, bir işletmenin maliyet etkinliğinin, teknik etkinlik ve tahsis etkinliği olmak üzere iki unsuru içerdiğini savunmuştur. Teknik etkinlik, bir firmanın veri girdiler setinden maksimum çıktıyı elde etme yeteneği olarak tanımlanmaktadır. Tahsis etkinliği ise, fiyatlar ve üretim teknolojisi veri iken, girdileri optimal oranlarda kullanma yeteneği olarak tanımlanmaktadır (Farrell, 1957: 254-255). Bu iki ölçü daha sonra toplam ekonomik etkinliğin ölçülmesi için birleştirilmiştir (Coelli, 1996: 3). 


\section{B. VZA ile Etkinlik Ölçülmesi}

Homojen karar birimlerinin göreli etkinliğini ölçmede kullanılan çok değişkenli verimlilik analiz modeli olan VZA'da, etkinliğin ölçümü Çıktıların Ağırlıklı Toplamı/ Girdilerin Ağılıklı Toplamı olarak hesaplanmaktadır (Talluri, 2000: 8). VZA'nın gelişimi ile teknik etkinlikle ilgili teorik çalışmalarda yenilikler olmuştur. Bu yeniliklerde Charnes, Cooper ve Rhodes (1978) ve Banker, Charnes ve Cooper (1984)'nin Farrell'a dayalı matematiksel yaklaşım ile etkin sınır tahminlemeleri etkili olmuştur. En iyi etkin sınırı belirlemede gözlem verilerini kaplayan bu VZA modelleri teknik etkinliğin değerlendirilmesinde yaygın olarak kullanılmaktadır (Ruggiero ve Bretschneider, 1998: 438).

Şekil 1: Teknik Etkinlik ve Tahsis Etkinliği

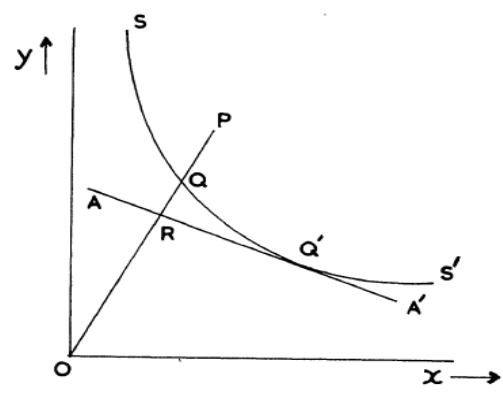

Kaynak: Farrell, 1957: 254

Farrell (1957), Şekil 1'de eş ürün ve eş maliyet eğrilerini kullanarak teknik etkinlik ve tahsis etkinliğini açıklamıştır. Eşürün eğrisi SS' (etkin sınır) üzerindeki gözlemler üretim imkanları kümesindeki diğer gözlemlere göre daha iyi performansa sahiptir. Bu nedenle, eş-ürün eğrileri ile etkin sınır kavramları aynı anlamda kullanılmaktadır. P biriminin tam etkin olabilmesi için SS' üzerinde yer alan $\mathrm{Q}$ birimi kadar girdi kullanmalıdır. $\mathrm{Bu}$ durumda $\mathrm{P}$ biriminin teknik etkinliği OQ/OP olarak bulunur (Farrell,1957: 254).

AA' eş maliyet doğrusu çıktı üretiminin belirli bir harcama sınırında yapılması zorunluluğunu ifade etmektedir. AA' üzerinde olan her birim fiyat etkinliğine ya da tahsis etkinliğine sahip olmaktadır. P biriminin tahsis etkinliği OR/OQ oranı ile hesaplanmaktadır (Farrell, 1957: 255).

Toplam maliyet etkinliği ise, bir ekonomik birimin minimum maliyet düzeyinde üretim yapmadaki başarısı olarak tanımlanmış olup teknik etkinlik ve tahsis etkinliğinin çarpımıyla hesaplanmaktadır. Toplam Maliyet Etkinliği: $\mathrm{OQ} / \mathrm{OP} * \mathrm{OR} / \mathrm{OQ}=\mathrm{OR} / \mathrm{OP}$ oranıla hesaplanmaktadır.

VZA'da teknik etkinlik, saf teknik etkinlik ve ölçek etkinliği olmak üzere birbirinden ayrık iki bileşene ayrılmıştır. Bu ayrılma kaynaklardaki etkinsizliğin nedenini anlamaya olanak sağlamaktadır. Saf teknik etkinlik ölçümü, ölçeğe göre değişken getiri varsayımı altında etkin sınır tahminlemesi yapılarak bulunabilir. $\mathrm{Bu}$ ölçek etkinliği olmadan teknik etkinliğin ölçüsüdür ve üretim sürecinde girdileri düzenlemek için yönetimsel performansı yansıtmaktadır. Teknik etkinliğin saf teknik etkinliğe oranı ölçek etkinliğini vermektedir. Ölçek etkinliğinin ölçümü, optimum kaynak büyüklüğünü seçmek için yönetim 
yeterliliğini sağlamaktadır (Kumar ve Gulati, 2008: 35). Uygun ölçek seviyesinde üretimin gerçekleştirilmesinde gösterilen başarı seviyesi ölçek etkinliği olarak ifade edilebilmektedir (Gökgöz, 2009: 17). Girdi miktarındaki artışın potansiyel üretim kapasitesini etkileyeceğini gösteren bir ekonomi tanımı olan ölçeğe göre getiri, ölçeğe göre artan getiri IRS (Increasing Returns to Scale), ölçeğe göre sabit getiri CRS (Constant Returns to Scale), ölçeğe göre azalan getiri DRS (Decreasing Returns to Scale) olmak üzere üç farklı şekilde gerçekleşebilmektedir (Wang ve Cui, 2010: 168).

\section{VZA MODELLERI}

Literatürde yaygın olarak kullanılan iki VZA modeli bulunmaktadır. Bu modeller, Charnes, Cooper ve Rhodes (1978) tarafından ortaya konulan ve ölçeğe göre sabit getiri varsayımına sahip olan CCR modeli, Banker, Charnes ve Cooper (1984) tarafından ortaya konulan ve ölçeğe göre değişen getiri varsayımına dayalı olan BCC modelidir (Charnes vd., 1994: 23).

CCR ve BCC modelleri arasındaki fark, Şekil 2'deki etkinlik sınırının görüntüsüyle daha iyi açıklanabilir. CCR modelinde tek girdi ve tek çıktı durumu için etkinlik sınırının şekli, ölçeğe göre sabit getiri varsayımından dolayı orjinden geçen bir doğru biçimindedir. BCC modelinde ise ölçeğe göre değişken getiri söz konusu olduğu için parçalı doğrusal ve iç bükeydir.

Şekil 2: CCR ve BCC Modelleri Etkinlik Sınırı

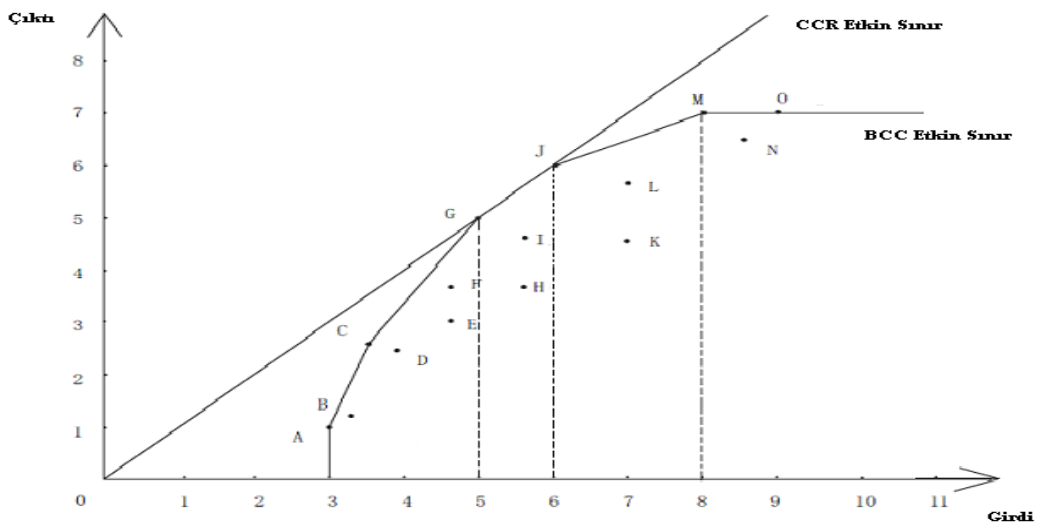

Kaynak: Wang ve Chui, 2010: 170

\section{A. CRR Modeli}

CCR modeli, teknik etkinlik ile ölçek etkinliğinin birleşimden oluşan toplam etkinliği ölçmektedir. CCR modelini kullanarak KVB'lerin göreceli etkinliklerinin belirlenmesinde, analiz edilen KVB'lerin etkin kabul edilebilmesi için hem teknik etkinliğe hem de ölçek etkinliğine sahip olmaları gerekmektedir. CCR modeli, "Girdi Yönlü CCR" ve "Çıktı Yönlü CCR" olmak üzere ele alınmaktadır (Gökgöz, 2009: 37).

\section{Girdi Yönlü CCR}

Girdi yönlü CCR modeli, asgari çıktı düzeyini karşılamak üzere girdilerin minimize edilmesini amaçlamaktadır (Cooper vd., 2000, s.41). Charnes vd. 
(1978) tarafından geliştirilen ilk model (Charnes vd., 1978: 430) kesirli programlama modelidir ve çözümü oldukça zordur (Ray, 2004: 29). Bu nedenle, model yeniden düzenlenerek doğrusal programlama (DP) modeline dönüştürülmüştür (Cooper vd, 2000: 23); K1sıt sayısının az olması ve yöneticilere önemli bilgiler sağlaması nedeniyle DP modelinin dual formu incelenerek Zarflama modeli oluşturulmuştur (Cooper vd. 2000: 43). Girdi yönlü CCR modeline ilişkin DP modeli ve Zarflama Modeli aşağıda verilmektedir.

DP MODEL

$$
\begin{aligned}
& \boldsymbol{E}_{0}=m a k s \sum_{r=1}^{s} \boldsymbol{u}_{r} \boldsymbol{y}_{r o} \\
& \text { Kistlar; } \\
& \sum_{i=1}^{m} v_{i} x_{i o}=1 \\
& \sum_{r=1}^{s} \boldsymbol{u}_{r} \boldsymbol{y}_{r j} \leq \sum_{i=1}^{m} \boldsymbol{v}_{i} \boldsymbol{x}_{i j} \\
& j=1,2, \ldots \ldots . n \quad \boldsymbol{v}_{i}, \boldsymbol{u}_{r} \geq \varepsilon \\
& r=1,2, \ldots \ldots . . S \quad i=1,2, \ldots \ldots . m
\end{aligned}
$$

\section{ZARFLAMA MODELI}

$$
E_{\mathrm{o}}=\min \theta-\varepsilon\left(\sum_{i=1}^{m} \boldsymbol{S}_{i}^{-}+\sum_{r=1}^{s} \boldsymbol{S}_{i}\right.
$$

Kisitlar;

$$
\begin{aligned}
& \sum_{j=1}^{n} x_{i j} \lambda_{j}-\theta X_{i o}+s_{i}^{-}=0 \\
& i=1,2, \ldots \ldots . . m \\
& \sum_{j=1}^{n} y_{r j} \lambda_{j}-y_{r o}-s_{r}^{+}=0 \\
& r=1,2, \ldots \ldots . s \\
& \lambda_{j}, \boldsymbol{S}_{i}^{-}, \boldsymbol{S}_{r}^{+} \geq 0 \quad r=1,2, \ldots \ldots . . \\
& i=1,2, \ldots \ldots . . m \\
&
\end{aligned}
$$

Zarflama modelinde, $\theta$ etkinlik skorunu göstermektedir (Coelli vd., 2005: 163). Diğer bir ifadeyle, $\theta$ etkin sınıra göre radyal uzaklıklara dayalı olarak hesaplanan etkinlik ölçümünü vermektedir. $\lambda_{j}$ değişkeni referans kümesinin belirlenmesinde kullanılmaktadır. $\lambda_{\mathrm{j}}>0$ olan karar birimleri etkin olarak değerlendirilir ve bu karar birimleri, etkin olmayanlar için referans kümesini oluştururlar (Tarım, 2001: 65). Modelde yer alan $\boldsymbol{S}_{i}^{-}$ve $\boldsymbol{S}_{r}^{+}$değişkenleri ise, sırasıyla girdilerdeki fazlalığı ve çıktılardaki eksikliği gösteren değişkenlerdir. $\boldsymbol{S}_{r}^{+}$ karar biriminin $r$ çıktısına ait ek artırımını gösteren negatif olmayan boşluk değişken değeri, $S_{i}^{-}$karar biriminin i girdisine ait ek azaltılmasını gösteren negatif olmayan boşluk değişken değeridir (Charnes vd.,1978: 433). Her bir girdi ve çıtı için $\theta=1$ ve $\boldsymbol{S}_{r}^{+}=\boldsymbol{S}_{i}^{-}=0$ olduğunda KVB etkin kabul edilmektedir (Zhu, 2009: 8)

\section{2. Çıktı Yönlü CCR}

Çıkt1 yönlü CCR modeli, sahip olunan girdi değerlerinin daha fazlasına ihtiyaç duymadan çıktı değerinin maksimize edilmesini amaçlamaktadır (Cooper vd., 2000: 41). Çıktı Yönlü CCR modeline ait, CCR modeline ilişkin DP modeli ve Zarflama Modeli aşağıda verilmektedir (Cooper vd. 2011: 11). 
DP MODELI

$\boldsymbol{E}_{\mathrm{o}}=\min \sum_{i=1}^{m} \boldsymbol{\nu}_{i} \boldsymbol{x}_{i o}$

Kisitlar;

$\sum_{r=1}^{s} \boldsymbol{u}_{r} \boldsymbol{y}_{r_{0}}=\mathbf{1}$

$\sum_{r=1}^{s} \boldsymbol{u}_{r} \boldsymbol{y}_{r j} \leq \sum_{i=1}^{m} \boldsymbol{v}_{i} \boldsymbol{x}_{i j}$

$j=1,2, \ldots \ldots . . . n$

$\boldsymbol{v}_{i}, \boldsymbol{u}_{r} \geq \varepsilon \quad r=1,2, \ldots \ldots s$

Illerin Kültürel Göstergelerine İlişkin Bir Uygulama

\section{ZARFLAMA MODELI}

$\operatorname{maks} \varphi+\varepsilon\left(\sum_{i=1}^{m} \boldsymbol{S}_{i}^{-}+\sum_{r=1}^{s} \boldsymbol{S}_{r}^{+}\right)$

Kistlar;

$\sum_{j=1}^{n} x_{i j} \beta_{j}-x_{i o}+s_{i}^{-}=0$

$i=1,2, \ldots \ldots . . . m$

$\sum_{j=1}^{n} y_{r j} \beta_{j}-\varphi y_{r o}-s_{r}^{+}=0$

$r=1,2, \ldots \ldots s$

$\boldsymbol{\beta}_{j}, \boldsymbol{S}_{i}^{-}, \boldsymbol{S}_{r}^{+} \geq 0 \quad r=1,2, \ldots \ldots s$

$i=1,2, \ldots \ldots . . m \quad j=1,2, \ldots \ldots . n$

$\varphi$; KVB'nin çıktılarının radyal olarak ne kadar artırılabileceğini belirleyen genişleme katsayısını, $\beta_{\mathrm{j}}$; Çıktıya yönelik modeller için $\mathrm{j}$. KVB'nin aldığı yoğunluk değerini (o. KVB' nin referans kümesinin alacağı değer) göstermektedir.

\section{B. BCC Modeli}

BCC modeli ise Banker, Charnes ve Cooper tarafindan (1984) ölçeğe göre getiri varsayımı altında etkinliği değerlendirmek için CCR modeline $\sum_{j=1}^{m} \lambda_{j}=1$ kisıtı eklenerek oluşturulmuştur (Cooper vd. 2011: 13). Eklenen bu konvekslik kısıtı ile ölçeğe göre değişen getirilerin dikkate alınması sağlanmaktadır. BCC modeli, Girdi Yönlü BCC ve Çıktı Yönlü BCC modeli olarak incelenmektedir.

\section{Girdi Yönlü BCC}

Girdi yönlü BCC kesirli programlama modeline göre oluşturulan DP modeli ve DP modelinin duali kullanılarak elde edilen girdi yönlü Zarflama Modeli aşağıdaki formdadır (Banker vd., 2004: 346-347);

\section{DP MODELi}

$$
\boldsymbol{E}_{0}=\operatorname{maks} \sum_{r=1}^{s} \boldsymbol{u}_{r} \boldsymbol{y}_{r o}-\boldsymbol{u}_{o}
$$

Kisitlar;

$\sum_{i=1}^{m} v_{i} x_{i o}=1$

$\sum_{r=1}^{s} \boldsymbol{u}_{r} \boldsymbol{y}_{r j}-\boldsymbol{u}_{o} \leq \sum_{i=1}^{m} \boldsymbol{v}_{i} \boldsymbol{x}_{i j}$

$j=1,2, \ldots \ldots . . n \quad v_{i}, u_{r} \geq \varepsilon$

$i=1,2, \ldots \ldots . . m$

\section{ZARFLAMA MODELi}

$\min \theta-\varepsilon\left(\sum_{i=1}^{m} \boldsymbol{s}_{i}^{-}+\sum_{r=1}^{s} \boldsymbol{s}_{r}^{+}\right)$

Kistlar;

$\sum_{j=1}^{n} x_{i j} \lambda_{j}-\theta x_{i o}+s_{i}^{-}=0$

$i=1,2, \ldots \ldots . . . m$

$r=1,2, \ldots \ldots . . s \quad \sum_{j=1}^{n} y_{r j} \lambda_{j}-y_{r o}-s_{r}^{+}=0$

$r=1,2, \ldots \ldots . . s$

$\sum_{j=1}^{n} \lambda_{j}=1 \quad \lambda_{j}, s_{i}^{-}, s_{r}^{+} \geq 0$

$r=1,2, \ldots \ldots s$

$i=1,2, \ldots \ldots \ldots . m \quad j=1,2, \ldots \ldots . . n$ 
Modelin nihai çözümünde $\mathrm{j}$ karar biriminin $\lambda_{\mathrm{j}}$ toplamı birden büyük ise KVB ölçeğe göre azalan getiride; $\lambda_{\mathrm{j}}$ toplamı birden küçük ise KVB ölçeğe göre artan getiride ve $\lambda_{\mathrm{j}}$ toplamı l' e eşitse KVB ölçeğe göre sabit getiride faaliyette bulunmaktadır.

\section{2. Çıktı Yönlü BCC}

Çıktı yönlü BCC kesirli programlama modelinden elde edilen DP modeli ve DP'nin duali alınarak oluşturulan çıktı yönlü zarflama modeli aşağıdaki gibidir (Tone, 1996: 609-610);

$$
\begin{aligned}
& \text { DP MODELI } \\
& E_{0}=\min \sum_{i=1}^{m} \boldsymbol{v}_{i} \boldsymbol{x}_{i o}-\boldsymbol{v}_{o} \\
& \text { Kisitlar; } \\
& \sum_{r=1}^{s} \boldsymbol{u}_{r} \boldsymbol{y}_{r o}=1 \\
& \sum_{r=1}^{s} \boldsymbol{u}_{r} \boldsymbol{y}_{r j} \leq \sum_{i=1}^{m} \boldsymbol{v}_{i} \boldsymbol{x}_{i j}-\boldsymbol{v}_{o} \\
& j=1,2, \ldots \ldots . n \boldsymbol{v}_{i}, \boldsymbol{u}_{r} \geq \varepsilon \\
& i=1,2, \ldots \ldots . . m
\end{aligned}
$$

$$
\begin{aligned}
& \text { ZARFLAMA MODELI } \\
& \boldsymbol{E}_{\mathrm{o}}=\operatorname{maks} \varphi+\varepsilon\left(\sum_{i=1}^{m} \boldsymbol{S}_{i}^{-}+\sum_{r=1}^{s} \boldsymbol{S}_{r}^{+}\right) \\
& \text {Kisitlar; } \\
& \sum_{j=1}^{n} x_{i j} \beta_{j}-x_{i o}+s_{i}^{-}=0 \\
& i=1,2, \ldots \ldots . . m
\end{aligned}
$$

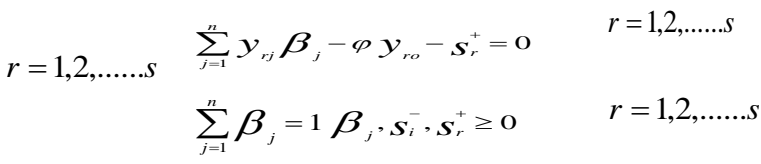

$$
\begin{aligned}
& i=1,2, \ldots \ldots . . m \quad j=1,2, \ldots \ldots . n
\end{aligned}
$$

BCC modelinde, $\lambda$ amaç denkleminin optimal değerinin bire eşit olduğu durumda ve ayn zamanda $\varphi=1$ ve ${\hat{\boldsymbol{S}_{i}}}_{-}^{-}{\boldsymbol{\boldsymbol { S } _ { r }}}^{+}=0$ olduğu durumda KVB etkinliğinden söz edilmektedir (Yun vd., 2004: 91).

\section{VZA'NIN UYGULAMA AŞAMALARI}

VZA'nın uygulanması üç temel adımda gerçekleşmektedir. Bu adımlar; analize girecek olan KVB'lerin belirlenmesi, seçilen KVB'lerin etkinliklerinin değerlendirilmesi için uygun girdi ve çıktı değişkenlerinin belirlenmesi, VZA modelleri uygulanarak KVB'lerin etkinlik sonuçlarının değerlendirilmesi olarak siralanmaktadir.

Analizde kullanılacak KVB'lerin belirlenmesi ilk ve en önemli aşamadır. KVB'ler girdileri çıktılara dönüştürebilen ekonomik birimler olmalıdırlar. Aynı zamanda, VZA karşılaştırmalı bir analiz olduğu için, analizin doğru sonuç vermesi KVB'lerin homojen olmalarına bağlidır (Golany ve Roll, 1989: 239). Bu doğrultuda seçilen KVB'ler aynı görevleri benzer amaçla yerine getirmeli, aynı koşullarda çalışmalı ve KVB'lerin performansını karakterize eden faktörler aynı olmalıdır. KVB'ler belirlenirken homojenlik ilkesinin yanı sira KVB'lerin sayısının belirlenmesi da oldukça önem taşımaktadır. Dyson vd. (2001) girdi ve çıktılarının toplamının en az iki katı kadar sayıda KVB belirlenmesi gerektiğini savunmuştur (Dyson vd. 2001: 248). Cooper vd. (2001) girdi sayısı ile çıktı sayısı toplamının 3 katından daha fazla sayıda KVB birimi olması gerektiğini 
belirtmişlerdir (Cooper vd., 2001: 219). Norman ve Stoker (1991), analize dahil edilen KBV sayısının en az yirmi olması gerektiği üzerinde durmaktadırlar.

VZA'nın uygulanmasında ikinci adım, analizde kullanılacak girdi ve çıktı değişkenlerinin seçimidir. VZA, veri tabanlı bir etkinlik ölçme tekniği olduğundan, ölçüm sonuçlarının doğru olması seçilen girdi ve çıtılların da anlamlı olması ile mümkündür. VZA uygulamasında, girdi ve çıktılar için farklı ölçü birimleri de kullanılabilmektedir. Bununla birlikte, VZA modelinin ayrıştırma yeteneğinin çok olabilmesi için girdi ve çıktı sayısının mümkün olabildiğince çok olması istenir. Seçilen girdi sayısı $\mathrm{m}$, çıktı sayısı da s ise en az $\mathrm{m}+\mathrm{s}+1$ tane KVB, araştırmanın güvenilirliği açısından gerekli bir kısıttır (Ertuğrul ve Işık, 2008: 205). VZA'da gerekli olmayan girdi ve çıktıların kullanılmasının önüne geçilebilmesi, ikili korelasyonların incelenmesi ile mümkün olmaktadır. Çıktı değişkenleri ile yüksek korelasyona sahip olmayan girdi değişkenlerinin analizden çıkartılması daha iyi sonuçların elde edilmesini sağlayacaktır.

VZA ile KVB'lerin etkinlikleri değerlendirilirken, $\mathrm{CCR}$ ve $\mathrm{BCC}$ modelleri kullanılabilmektedir. CCR modeli toplam teknik etkinliği bir bütün olarak hesaplarken, BCC modeli ise, teknik etkinliği ve ölçek etkinliğini ayırarak hesaplama yapma imkânı sağlamaktadır. Analiz sadece, incelemeye alınan KVB'lerin oluşturulduğu gözlem seti için gerçekleştirildiğinden, mühendislik ve temel bilimlerde hesaplanabildiği şekliyle mutlak etkinlik değil, göreli etkinlik değerlendirmesi yapmaktadır (Karahan ve Özgür, 2009, s. 110-111).

CCR ve BCC modelleri girdi ve çıktı yönlü olmak üzere uygulanabilmektedir. Çıktı yönlü CCR ve BCC modelleri, girdileri sabit tutarak çıktıların ne oranda artırılması gerektiğini incelemektedir. Girdi yönlü CCR ve BCC modelinde ise, belirli bir çıktı bileşimini üretebilmek için kullanılacak en uygun girdi bileşimini elde etmeyi amaçlamaktadır.

VZA'nın uygulanmasındaki son adım, amaca en uygun VZA modelini kullanarak KVB'lerin etkinlik sonuçlarının hesaplanması ve elde edilen bu etkinlik sonuçlarının değerlendirilmesidir. VZA ile etkinlik karşılaştırılmasına tabi tutulan tüm KVB'lerin kaynaklarını verimli kullanıp kullanmadığı tespit edilir, girdi ve çıktı değişkenlerinde herhangi bir gelişme potansiyelinin bulunup bulunmadığı belirlenir, KVB'lerin girdi ve çıktı değişkenleri kapsamında iyileştirilebilmesi amaciyla rasyonel öneriler sunulabilir (Gökgöz, 2009: 31).

\section{KÜLTÜREL GÖSTERGELER KULLANILARAK ILLERIN ETKINLIKLERININN VZA İLE KARŞILAŞTIRILMASI}

Kültür geniş anlamda bireylerin içerisinde yaşadıkları sosyal çevre ve şartlar olarak tanımlanabilir (Erdem vd., 2010: 74). Kültür, bir toplumun ya da sosyal grubun, ayırt edici maddi, manevi, entelektüel ve duygusal özelliklerinin bir kümesi olarak kabul edilmelidir. Bu kapsama, sanat ve edebiyat, yaşam tarzı, birlikte yaşama yolları, değer sistemleri, gelenekler ve inançlar da dahil edilebilir (UNESCO, 2001: 2). Kültür, bir insan topluluğu arasında paylaşılan yaşamı sürdürmeye yönelik olarak tasarlanmış değerler ve normlar sistemi şeklinde ele alınmaktadır (Hill, 2002: 79). Kültür; insanlar arası etkileşimin bir sonucudur. 
İnsanların, sosyal davranış geliştirmek ve deneyimlerini yorumlamak için kullandıkları kazanılmış birikimleridir (Vern ve Kenneth, 1985: 6-7).

Kültür, hem küresel hem de ulusal düzeyde istihdam, gelir ve ciro oluşturmak üzere yardımcı olan dinamik ve yenilikçi ekonomik bir güçtür. Buna bağlı olarak ekonomik büyümede ve sosyal dışsallığın üretilmesinde önemli bir etkendir. Yayıncılık, sahne sanatları, görsel-işitsel el sanatları ve tasarım gibi mal ve hizmet oluşturma, üretim ve dağıtım gibi faaliyetlerin gerçekleştirildiği kültürel ve yaratıcı sektörler, 2007 y1lında küresel GSYH'nin \%3,4'üne $(1,6$ trilyon $\mathrm{ABD}$ doları) karşılık gelmektedir. Bu rakamın o sene içerisinde uluslararası turizm gelirlerinin neredeyse iki katına eşit olması dikkat çekicidir (UNESCO, 2011: 5). 2000-2005 periyodu içinde ise, uluslararas1 yaratıcı mal ve hizmet ticareti, \%8,7 ile görülmemiş bir yıllık büyüme oranına sahip olmuştur (UN, 2008, s. 4). Bir başka gösterge olan sektör içerisindeki çalışan nüfus sayısı, 2004 yılında, 5,8 milyon çalışan ile Avrupa Birliği toplam çalışan nüfusunun \%3,1'ine karş1lık gelmiştir (KEA, 2006: 6). Bütün bu yukarıda sayılan istatistikler, kültürel ve yaratıcı endüstrilerin 21.yy'da en umut verici sanayi kolları olarak karşımıza çıkacağını göstermektedir.

Kültürel ve yaratıcı sektörler yarattıkları katma değer ile ülkelerinin sürdürülebilir ekonomik kalkınmalarının sağlanmasına yardımcı olmaktadırlar. Ülkelerin kültür ekonomisi kapsamında faaliyet gösteren sektörlerdeki gelişmeleri sağlayabilmeleri ve bu sektörleri yönetebilmeleri ancak, ilgili istatistiksel göstergelerin sağlıklı bir şekilde seçilmesi ve veri bankasının yapılandırılması ile mümkün olabilecektir (Özdemir, 2009: 79-80).

Eğitim, nüfus ve sağlık gibi diğer sosyal istatistiklerin aksine, mevcut kültürel istatistikler, yaratıcı ve kültürel sektörler içerisinde gerçekleştirilen faaliyetlerin az bir kısmını kapsamaktadır. Pazarlanabilir kültürel mal ve hizmetlerin üretilmediği ülkelerin varlığı, parasal olarak ölçülemeyen kültürel faaliyetlerin istatistiklerinin tutulmaması, ülkede yaşayanların kültürel mal ve hizmetleri tüketmediği durumların varlığı ve az gelişmiş ülkelerde kültür istatistiklerinin elde edilmesi için yeterli kaynak ayrılmaması gibi sorunlar nedeniyle kültürel istatistiklerin toplanması ve veri tabanlarının oluşturulmasında bazı zorluklar bulunmaktadır (Goldstone, 1999: 45-46). Ayrıca, kültürel göstergeler literatürde siklıkla kültürel gelişmişliğin bir ölçüsü olarak kabul görmesine rağmen, birimler arası karşılaştırılabilir göstergelerin hala sınırlı gelişme gösterdiği göz önüne alındığında, karşılaştırma yapmak için tek bir tip strateji izlemek de mümkün olmamaktadır.

Kültürel ve yaratıcı sektörlerin gelişmesine paralel olarak karşılaştırılabilir kültürel istatistikler elde etmek için birçok ülkede ve uluslararası kuruluşlarda çalışmalar yapılmaktadır. Bu amaçla, Avrupa'da 2009 yılında Avrupa İstatistik Birimi'ne bağl1, Avrupa Kültür İstatistikleri Sistem Ağ kurulmuştur. Bu birimin 2012 yılında yayınladığı raporda, Kültür İstatistikleri Öncü Grubu'nun (LEG-Kültür) 2000 y1lında belirlediği kültürel göstergelere üç yeni gösterge eklenmiştir. UNESCO bünyesinde de uzun yıllardan beri sürdürülen kültür istatistiklerine yönelik olan çalışmalar, 2009 yılında yayınlanan Kültür 
İstatistikleri için Çerçeve isimli çalışmayla yeni bir aşamaya girmiştir. Kültürel göstergelere ilişkin Avrupa ve UNESCO arasında yapılan karşılaştırma Şekil 3'te sunulmaktadir.

Şekil 3: Kültürel Göstergelerin Karşılaştırılması

Kültür İstatistikleri
Öncü Grubu (LEG-
Kültür) Kültür
Raporu (2OOO)

- Tarihsel Anit

- Müzeler

- Arkeolojik Siteler

- Arşivler

- Kütüphaneler

- Kitaplar ve Basım

- Haber Ajansları

- Görsel Sanatlar (Tasarim Dahil)

- Fotoğraflar

- Mimarlık

- Sahne Sanatları

- Filmler

- Radyo

- Televizyon

- Video

- Ses Kayıtları

- Multimedya

Kaynak: Bina vd., 2012

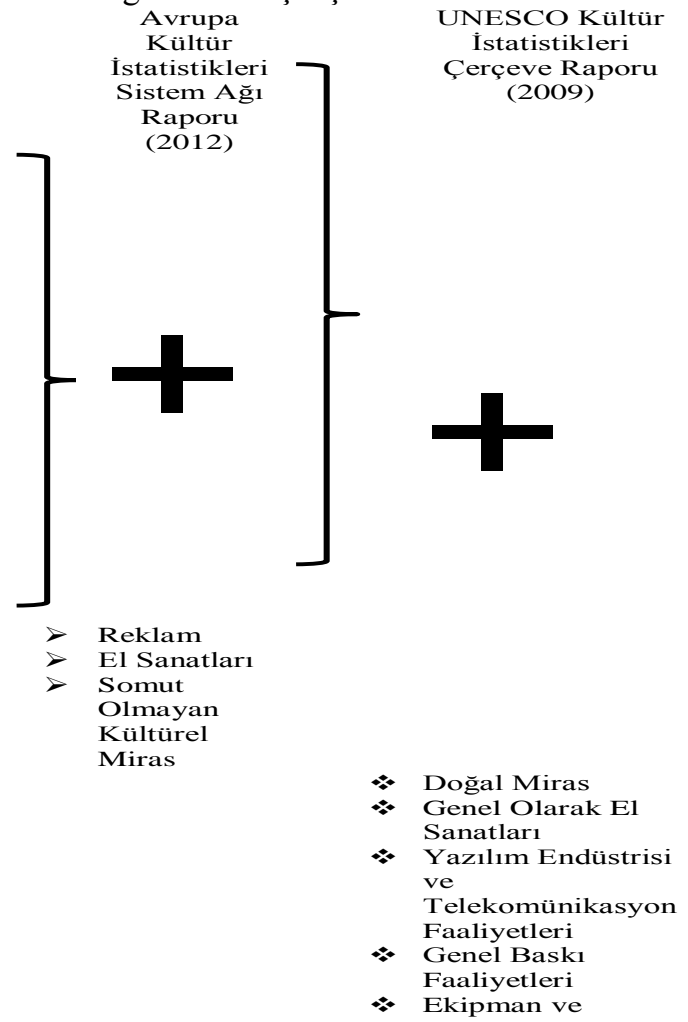

Ülkemizde Türkiye İstatistik Kurumu (TUIK) tarafından derlenen kültür istatistikleri, ilk olarak 1959 y1lında Milli Kütüphane, halk, çocuk, üniversite ve okul kütüphanelerine ilişsin bilgilerin derlenmesiyle beraber TUIK yayınlarında yer almaya başlamıştır. Sinema, tiyatro, stadyum ve diğer eğlence yerlerine ilişkin bilgiler ise ilk kez, Kültür ve Eğlence Yerleri İstatistiklerinin 1970 y1lında derlenmesiyle beraber kullanıma sunulmuştur (TUIK, 2012). 2012 y1lı itibariyle kültür istatistikleri başlığı altında, kültürel miras, arşivler, kütüphaneler, kitaplar, gazeteler ve dergiler, sanat galerileri, tiyatrolar, operalar ve baleler, orkestra kadro ve topluluklar, sinemalar, fuarlar, belirli gün ve haftalar, kültürel eğitim, inanç, kültürel mal dış ticareti ve hanehalkı kültür harcamaları alanlarında istatistikler derlenmektedir. Şekil 3'te verilen başlıklar incelendiğinde TUİK tarafından verilen kültür istatistik alanlarının pek de yeterli ve istenen niteliklere sahip olmadığg görülmektedir. 
Tablo 1: Kültürel Ekonomi Alanında Yapılan VZA Çalışmaları

\begin{tabular}{|c|c|c|c|c|}
\hline Alan & VZA Modeli & Girdi Değișkenleri & Çıktı Değişkenleri & Yazarlar \\
\hline Müzeler & $\begin{array}{l}\text { CCR Çikt } \\
\text { Odaklı }\end{array}$ & $\begin{array}{l}\text { - Alan }\left(\mathrm{m}^{2}\right) \text { ve yılda } \\
\text { toplam müze açık } \\
\text { kalma zamamı } \\
\text { - Müzedeki çalışan } \\
\text { sayısı } \\
\text { - Sosyal tesis ve } \\
\text { kullanulan bilgi } \\
\text { teknolojileri } \\
\text { - Tamunm faaliyetleri }\end{array}$ & $\begin{array}{l}\text { - Bir yıldaki toplam } \\
\text { ziyaretçi sayısı }\end{array}$ & $\begin{array}{l}\text { (Taheri \& } \\
\text { Ansari, } \\
\text { 2013) }\end{array}$ \\
\hline Müzeler & $\begin{array}{l}\text { CCR ve BCC } \\
\text { Girdi Odaklı }\end{array}$ & $\begin{array}{l}\text { - Çalıgan Sayısı } \\
\text { - Sergi Odası Sayısı } \\
\text { - Ekipman }\end{array}$ & $\begin{array}{l}\text { - Ziyaretçi Sayısı } \\
\text { - Organize edilen } \\
\text { sumumlann açık } \\
\text { olduğu ortalama gün } \\
\text { sayısı } \\
\text { - Düzenlenen } \\
\text { organizasyon sayısı } \\
\text { - Yeni alıan veya } \\
\text { kiralanan materyal } \\
\text { sayısı }\end{array}$ & $\begin{array}{l}\text { (Barrio \& } \\
\text { Herrero, } \\
2013 \text { ) }\end{array}$ \\
\hline Rūtüpbane & $\begin{array}{l}\text { CCR Girdi } \\
\text { Odaklı ve BCC } \\
\text { Çıkn Odaklı }\end{array}$ & $\begin{array}{l}\text { - Kitap Sayısı } \\
\text { - Kürû́phane Alanı }\left(\mathrm{m}^{2}\right) \\
\text { - Çalışsan sayısı } \\
\text { - Gelişmişlik endeksi }\end{array}$ & $\begin{array}{l}\text { - Kürüphane üye } \\
\text { sayısi/Nüfus } \\
\text { - Kürüphane Çalıģan } \\
\text { Sayısı/Nüfus } \\
\text { - Kürüphane kullanıc1 } \\
\text { sayısı/Nüfus } \\
\text { - Ödünç verilen kitap } \\
\text { sayısı }\end{array}$ & $\begin{array}{l}\text { (Alkdede \& } \\
\text { Kazancoglu, } \\
2006 \text { ) }\end{array}$ \\
\hline Kütüphane & $\begin{array}{l}\text { CCR çıkn } \\
\text { odaklı }\end{array}$ & $\begin{array}{l}\text { - Tam zamanli çalıģan } \\
\text { kişi sayısı } \\
\text { - Materyal sayısı }\end{array}$ & $\begin{array}{l}\text { - Abone oluman yayn } \\
\text { sayısı } \\
\text { - Toplam sirkūlasyon } \\
\text { - Haftada ortalama } \\
\text { calıșma zamanı (saat) } \\
\text { - Yulda envantere } \\
\text { eklenen materyal } \\
\text { sayıs }\end{array}$ & $\begin{array}{l}\text { (Reichmann, } \\
\text { 2004) }\end{array}$ \\
\hline Tiyatro & $\begin{array}{l}\text { Malquist } \\
\text { Indelks }\end{array}$ & $\begin{array}{l}\text { - Sergilenen farklı } \\
\text { performans sayısı } \\
\text { - Kapasite } \\
\text { - Performans için } \\
\text { barcanan miktar } \\
\text { - Sübvansiyon edilen } \\
\text { miktar }\end{array}$ & $\begin{array}{l}\text { - Sergilenen } \\
\text { performans sayısı }\end{array}$ & $\begin{array}{l}\text { (Marco- } \\
\text { Serramo, } \\
\text { 2006) }\end{array}$ \\
\hline Müze & $\begin{array}{l}\text { CCR girdi } \\
\text { odakli }\end{array}$ & $\begin{array}{l}\text { - Müze çalışan sayısı } \\
\text { - Sergi alami }\end{array}$ & $\begin{array}{l}\text { - Ziyaretçi geliri } \\
\text { - Sergi süresi } \\
\text { - Aktiviteler (seminer, } \\
\text { konferans, araşturama } \\
\text { proje sayısı }\end{array}$ & $\begin{array}{l}\text { (Basso \& } \\
\text { Fumari, } \\
\text { 2004) }\end{array}$ \\
\hline $\begin{array}{l}\text { Bolge, } \\
\text { Spehir }\end{array}$ & $\begin{array}{l}\text { Iiki aşamalı } \\
\text { VZA }\end{array}$ & $\begin{array}{l}\text { - Devlet tesvilkleri } \\
\text { - Üreticiler }\end{array}$ & $\begin{array}{l}\text { - Katilim } \\
\text { - Faaliyet gelirleri }\end{array}$ & $\begin{array}{l}\text { (Chang, } \\
\text { Ting, \& } \\
\text { Lee, 2012) }\end{array}$ \\
\hline $\begin{array}{l}\text { Bolge, } \\
\text { Sehir }\end{array}$ & $\begin{array}{l}\text { Süper Aylak } \\
\text { Tabanli VZA } \\
\text { Modeli }\end{array}$ & $\begin{array}{l}\text { - Kamu Yaturumları } \\
\text { - Teşvik Belgeli } \\
\text { Yaturumlar } \\
\text { - Banka Kredileri }\end{array}$ & $\begin{array}{l}\text { - Diş Ticaret Dengesi } \\
\text { - GSYiH } \\
\text { - Teşviklerle Yaranlan } \\
\text { Istihdam } \\
\text { - Açalan Issyeri Sayıs }\end{array}$ & $\begin{array}{l}\text { (Kuran, } \\
\text { 2008) }\end{array}$ \\
\hline $\begin{array}{l}\text { Bolge, } \\
\text { Sehir }\end{array}$ & $\begin{array}{l}\text { Farklı değişken } \\
\text { sayılanyla } \\
\text { VZA modelleri }\end{array}$ & $\begin{array}{l}\text { - } 11 \text { Girdi (İstihdam, } \\
\text { enerji ve gelişmişlikk } \\
\text { göstergeleri) }\end{array}$ & $\begin{array}{l}\text { - } 19 \text { Çılktı } \\
\text { (Demografik, sosyo- } \\
\text { ekonomik } \\
\text { göstergeleri) }\end{array}$ & $\begin{array}{l}\text { Atan vd., } \\
(2004)\end{array}$ \\
\hline
\end{tabular}

Literatürde bölgelerin veya ülkelerin bu göstergelere göre toplu olarak değerlendirmesini ele alan çalışma sayısının azlığı dikkat çekmektedir. Ancak, kültürel göstergeler olarak karşımıza çıkan tiyatro, kütüphane, müze ve kültürel miras gibi unsurlara ait istatistiklere ilişkin, göreli etkinlikleri karşılaştırma amacı güden çalışmalara rastlanabilmektedir. Yukarıda Tablo 2'de bu göstergelere ilişkin yapılmış bazı örnek çalışmalar verilmektedir.

\section{UYGULAMA}

$\mathrm{Bu}$ çalışmada, illerin kültürel ve yaratıcı sektörlerinin etkinlik değerlerinin VZA ile karşılaştırılabilmesi için 2012 yılı Kültür İstatistikleri yayınında yer alan illere ait veriler kullanılmıştır. Bu veriler içerisinden 
Türkiye'de illerin kültürel etkinliklerinin değerlendirmesinde kullanılan göstergeler girdi ve çıktı değişkenleri olarak seçilmiş ve Tablo 3'de gösterilmiştir.

Tablo 4: Çalışmada Kullanılan VZA Girdi ve Çıktı Değişkenleri

\begin{tabular}{|l|l|}
\hline Girdi Değiș kenle ri & Çlktı Değiş kenle ri \\
\hline Matbaa sayısı (I1) & $\begin{array}{l}\text { Özel ve özel olmayan müze ve ören yeri } \\
\text { ziyaretçi sayısı (O1) }\end{array}$ \\
\hline $\begin{array}{l}\text { Özel ve özel olmayan müze ve ören yeri } \\
\text { sayısı (I2) }\end{array}$ & $\begin{array}{l}\text { Halk kütüphanelerinde ödünç verilen } \\
\text { materyal sayısı (O2) }\end{array}$ \\
\hline Halk kütüphanesi kitap sayısı (I3) & Yayınlanan materyal sayısı (O3) \\
\hline Kitap dışı materyal sayısı (I4) & Satılan kitap bandrol adedi (O4) \\
\hline Yayımcı sayısı (I5) & Tiyatro seyirci sayısı (O5) \\
\hline Tiyatro toplam koltuk sayısı (I6) & Sinema seyircisi sayısı (O6) \\
\hline Sinema toplam koltuk sayısı (I7) & \\
\hline Okuma yazma bilen kişi sayısı (15+) (I8) & \\
\hline Taşımmaz kültür varlıkları (I9) & \\
\hline Eski eser sayısı (I10) & \\
\hline
\end{tabular}

VZA'da kullanılan girdi ve çıktı değişkenlerine ait ikili korelasyon katsayılarının incelenmesi anlamlı değişken kümelerinin kullanılıp kullanılmadığının araştırılması için etkili bir yöntemdir. Analizde kullanılan girdi ve çıktı değişkenlerine ait korelasyon katsayıları Tablo 5'te verilmektedir. Değişkenler arasında hesaplanan bütün korelasyon katsayıları $\alpha=0.01$ için anlamlıdır. Korelasyon katsayıları incelendiğinde, en küçük korelasyon katsayısının 0,34 olduğu görülmektedir. En yüksek korelasyon katsayısı da 0,99 olarak hesaplanmıştır.

Tablo 6: Değişkenler Arası Korelasyon Katsayıları

\begin{tabular}{|ll|l|l|l|l|l|l|l|l|l|l|}
\cline { 3 - 13 } \multicolumn{1}{c|}{} & & 11 & 12 & 13 & 14 & 15 & 16 & 17 & 18 & 19 & 110 \\
\hline O1 & Pearson Kor. Kat. & 0,91 & 0,79 & 0,73 & 0,92 & 0,87 & 0,90 & 0,91 & 0,91 & 0,95 & 0,90 \\
\hline O2 & Pearson Kor. Kat. & 0,35 & 0,56 & 0,60 & 0,15 & 0,42 & 0,34 & 0,27 & 0,40 & 0,25 & 0,36 \\
\hline O4 & Pearson Kor. Kat. & 0,98 & 0,76 & 0,82 & 0,92 & 0,97 & 0,84 & 0,97 & 0,94 & 0,89 & 0,83 \\
\hline O5 & Pearson Kor. Kat. & 0,97 & 0,72 & 0,77 & 0,96 & 0,95 & 0,85 & 0,98 & 0,93 & 0,92 & 0,84 \\
\hline O6 & Pearson Kor. Kat. & 0,99 & 0,80 & 0,79 & 0,93 & 0,96 & 0,92 & 0,97 & 0,99 & 0,94 & 0,89 \\
\hline
\end{tabular}

İllerin kültürel etkinlik düzeylerinin ölçülmesinde 10 adet girdi değişkeni ve 6 adet çıktı değişkeni kullanılmaktadır. Türkiye'deki 81 adet il VZA'daki KVB sayısını oluşturmaktadır. 81 adet ilin kültürel etkinliklerinin değerlendirilmesindeki girdi ve çıktı değişkenlerine ait tanımlayıcı istatistikler Tablo 7'te verilmiştir. 
Tablo 8: Tanımlayıcı İstatistikler

\begin{tabular}{|c|c|c|c|c|c|}
\hline \multirow{10}{*}{ 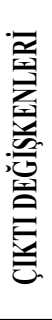 } & & O1 & O2 & $\mathbf{O 3}$ & O4 \\
\hline & Ortalama & 447103,77 & 74726,14 & 526,25 & 3620464,49 \\
\hline & Stds apma & 1543303,12 & 66355,20 & 3004,62 & 24723781,29 \\
\hline & Maks & 13001173,00 & 310978,00 & 24817,00 & 213372690,00 \\
\hline & Min & $\mathrm{O}$ & 4199 & $\mathrm{O}$ & $\mathrm{O}$ \\
\hline & & O5 & O6 & & \\
\hline & Ortalama & 69395,88 & 481508,52 & & \\
\hline & Stds apma & 222110,77 & 1616257,11 & & \\
\hline & Maks & 1881176,00 & 14000678,00 & & \\
\hline & Min & $\mathrm{O}$ & $\mathrm{O}$ & & \\
\hline \multirow{15}{*}{ 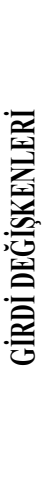 } & & I1 & $\mathbf{I 2}$ & $\mathbf{I 3}$ & \\
\hline & Ortalama & 102,95 & 5,89 & 194880,00 & \\
\hline & Stds apma & 319,59 & 9,57 & 177828,90 & \\
\hline & Maks & 2676,00 & 58,00 & 1179256,00 & \\
\hline & Min & 3 & $\mathrm{O}$ & 35820 & 14 \\
\hline & & $\mathbf{I} 4$ & I5 & I6 & I7 \\
\hline & Ortalama & 1655,57 & 22,43 & 2632,53 & 3011,74 \\
\hline & Stds apma & 7086,60 & 71,92 & 6963,89 & 10315,06 \\
\hline & Maks & 64683,00 & 555,00 & 55999,00 & 90813,00 \\
\hline & Min & 14,00 & $\mathrm{O}, \mathrm{OO}$ & $\mathrm{O}, \mathrm{OO}$ & $\mathrm{O}, \mathrm{OO}$ \\
\hline & & I8 & I9 & I10 & \\
\hline & Ortalama & 504711,84 & 1162,54 & 253,56 & \\
\hline & Stds apma & 1153790,89 & 3353,49 & 379,71 & \\
\hline & Maks & 9595922,00 & 29767,00 & 3186,00 & \\
\hline & Min & 27150,00 & 27,00 & 9,00 & \\
\hline
\end{tabular}

VZA ile illerin kültürel etkinlikleri değerlendirilirken, çıktı yönlü CCR ve BCC modelleri kullanılmıştır. Çıktı yönlü CCR ve BCC modellerinin analizde kullanılmasının nedeni, girdileri sabit tutarak çıktıların ne oranda artırılması gerektiğini incelemektir. Diğer bir ifadeyle, illerin kültürel etkinliğinin iyileştirilmesinde, kültürle ilgili sunulan hizmetlerden yararlanmanın ne düzeyde arttırılması gerektiğini belirlemektir.

Analize dahil edilen illere ait her iki VZA modeline göre hesaplanan etkinlik değerleri, DEAP 2.1 programı yardımıyla bulunmuştur. Çıktı yönlü CCR modele ve BCC modele göre hesaplanan illerin etkinlik skorlarının frekansları Tablo 9'te verilmiştir.

Tablo 10: CCR ve BCC Etkinlik Değerleri Frekansları

\begin{tabular}{|c|c|c|c|c|}
\hline \multicolumn{2}{|c|}{ Etkinlik De ğe rle ri } & \multirow{2}{*}{ CCR } & \multirow{2}{*}{ B CC } & \multirow{2}{*}{ Ölçek } \\
\hline Alt Limit & Üst Limit & & 6 & 1 \\
\hline 0 & 0.4999 & 8 & 2 & 1 \\
\hline 0.5 & 0.5999 & 3 & 2 & 1 \\
\hline 0.6 & 0.6999 & 2 & 4 & 0 \\
\hline 0.7 & 0.7999 & 6 & 6 & 5 \\
\hline 0.8 & 0.8999 & 4 & 1 & 16 \\
\hline 0.9 & 0.9999 & 2 & 60 & 57 \\
\hline
\end{tabular}

Çıktı yönlü CCR modeline göre illerin kültür etkinlikleri değerlendirildiğinde, 81 ilin 56'sının 1 etkinlik skoruyla etkin olduğu 
görülmüştür. Etkinlik skorlarının en düşük olduğu iller Afyon, Erzincan, Kahramanmaraş, Karabük, Kars, Mardin, Tokat ve Yozgat'tır.

Çıktı yönlü BCC modeline göre illerin kültür etkinlikleri değerlendirildiğinde ise 81 ilin 60'ının 1 etkinlik skoruyla etkin olduğu görülmüştür. BCC'ye göre etkinlik skorlarının en düşük olduğu iller Afyon, Erzincan, Maraş, Kars, Mardin ve Tokat'tır. Ayrıca, CCR modelinde etkin olmayan Elazığg, Karabük, Manisa, Mersin illeri BCC modeline göre etkindir. Sonuçların farklı çıkmasının nedeni, BCC modeline göre teknik olarak etkin olan illerin, ölçek etkinliğini sağlayamadıklarından toplam etkinlik ölçümü yapan CCR modeline göre etkin bulunmamışlardır.

BCC teknik etkinlik ve ölçek etkinlik skorlarının bağımsız olarak ölçülebilmesine imkan verdiğinden dolayı bu model ile her bir il için ölçek etkinliği hesaplanmış ve ölçeğe göre getirinin yönü belirlenmiştir. Buna göre, 8 ilin ölçeğe göre azalan getiriye sahip olduğu görülmüştür. Bu iller teknik etkinliğe sahip olup, ölçek etkinliğinde yeterli düzeyde olmadıkları için toplam teknik etkinliğe göre etkin olmayan iller arasındadırlar. Bu illerin çıktılarındaki artış girdilerindeki artış oranından daha az olmasından dolayı kaynaklarını yetersiz kullandıkları söylenebilir. Diğer taraftan, ölçeğe göre artan getiriye sahip 16 ilin ölçek etkinliğine sahip olmamasının nedeni ise, bir birim girdi ile bir birimden daha fazla çıktı üretebilecekken dışsal faktörlerden dolayı kapasitelerinin altında çıktı üretmelerinden kaynaklanmaktadır.

VZA KVB'lerin etkinlik skorlarını belirlemenin yanında etkin olmayan KVB'lerin etkin hale gelmeleri için gerekli olan iyileştirmeleri hesaplamayı da sağlamaktadır. Çalışmada yalnızca, her iki modele göre de etkin olmayan Afyon, Erzincan, Maraş, Kars, Mardin ve Tokat illeri için iyileştirme önerileri getirilmiştir. $\mathrm{Bu}$ iller için önerilen iyileştirmeler ise, çıktı yönlü BCC analizi sonuçları dikkate alınarak ifade edilmiştir.

Afyon'un kültürel açıdan etkin olabilmesi için, müze ve ören yeri ziyaretçi sayısının 247573'e, kütüphaneden ödünç verilen kitap sayısının 94087'ya, yayınlanan materyal sayısının 68433'e, satılan kitap bandrol sayısının 244822'ye, tiyatro izleyici sayısının 20494'e, sinema seyirci sayısının 260411'e yükseltilmesi gerekmektedir. Erzincan'ın etkin olabilmesi için, müze ve ören yeri ziyaretçi sayısının 32711'e, kütüphaneden ödünç verilen kitap sayısının 69446'ya, yayınlanan materyal sayısının 26886'ya, satılan kitap bandrol sayısının 130698'e, tiyatro izleyici sayısının 8182'ye, sinema seyirci sayısının 36661'e çıkarılması gerekmektedir. Maraş'ın etkin olabilmesi için, müze ve ören yeri ziyaretçi sayısının 48669'a, kütüphaneden ödünç verilen kitap sayısının 50199'a, yayınlanan materyal sayısının 116607'ye, satılan kitap bandrol sayısının 188004'e, tiyatro izleyici sayısının 52777'ye, sinema seyirci sayısının 391855'e çıkarılması önerilmektedir. Kars'ın etkin olabilmesi için, müze ve ören yeri ziyaretçi sayısını 112150'ye, kütüphaneden ödünç verilen kitap sayısını 38011'e, yayınlanan materyal sayısını 38820'ye, satılan kitap bandrol sayısını 223907'ye, tiyatro izleyici sayısını 7912'ye, sinema seyirci sayısını 29530'a yükseltmesi gerekir. Mardin'in etkin olabilmesi için, müze ve ören yeri ziyaretçi sayısını 
332771'e, kütüphaneden ödünç verilen kitap sayısını 399348'e, yayınlanan materyal sayısını 69799'a, satılan kitap bandrol sayısinı 450837'ye, tiyatro izleyici sayısını 20349'a, sinema seyirci sayısını 112376'ya çıkarması önerilmektedir. Tokat'ın etkin iller arasına girebilmesi için, müze ve ören yeri ziyaretçi sayısını 124268'e, kütüphaneden ödünç verilen kitap sayısını 79997'ye, yayınlanan materyal sayısını 44350'ye, satılan kitap bandrol sayısını 38506'ya, tiyatro izleyici sayısını 14695 'e, sinema seyirci sayısını 279921'e çıarması gerekmektedir. Çalışmada hesaplanan etkinlik değerleri ve getirilen iyileştirme önerileri analize dahil edilen değişken kümesi ile sınırlıdır.

\section{Sonuç}

VZA, etkinlik analizinde kullanılan diğer yaklaşımların zayıf oldukları durumlarda, az sayıda varsayıma sahip olduğundan daha rahat kullanılabilen bir yöntemdir. Geleneksel yöntemlerin çoklu girdi ve çoklu çıktıların değerlendirilmesi için sağlayamadıkları bütünselliği toplam faktör verimliliği mantığı ile sağlayabilmektedir. Yöntemin üretim sürecini tahmin için analitik bir fonksiyona (regresyondaki gibi) gerek duymaksızın kullanılabilmesi, birçok girdi ve çıktıyı aynı anda değerlendirebilmesi, sonuçta göreli olarak etkin ve etkin olmayan karar birimlerini birbirinden ayırarak, etkin olmayanlar için etkin olanlardan oluşan referans grupları ve ulaşabilecekleri hedefler belirlemesi tercih edilme nedenlerindendir. VZA, kamu kuruluşları (eğitim, sağlık, sosyal hizmetler) başta olmak üzere, özel sektör alanında da çok geniş bir kullanıma sahiptir. Özellikle tedarik zinciri, bankalar, üniversiteler, hastaneler, eğitim kurumları, belediyeler gibi değişik alanlarda faaliyet gösteren KVB'lerin göreli etkinliklerinin değerlendirilmesinde kullanılmaktadır. Son yıllarda ise, ülkelerin sağlık, eğitim, adalet gibi sosyal sistemlerinin değerlendirilmesinde de kullanılmaya başlanan VZA, müzeler, kütüphaneler, şehirlerin kültürel yaratıcılıkları gibi bir ülkenin kültürel değerlerini oluşturan KVB'lerin göreli etkinliklerinin değerlendirilebilmesi için de uygulanmaktadır.

Bir toplumun ya da sosyal grubun, ayırt edici maddi, manevi, entelektüel ve duygusal özelliklerinin bir kümesi olarak kabul edilen kültür, dünya ticareti içerisinde önemli paya sahip olan bir sektör olarak karşımıza çıkmaktadır. Dünyada ve Avrupa'da birçok şehir sahip olduğu kültürel değerleri ile marka olma konusunda önemli adımlar atmaktadır. Özellikle UNESCO ve AB karşılaştırılabilir kültürel göstergelerin neler olabileceği konusunda çalışmalar yapmaktadırlar. Bu kapsamda elde ettikleri karşılaştırllabilir kültürel göstergeler ile kültürel ve yaratıcı ve sektör içerisindeki değerlerin ekonomik olarak ölçülebilir hale gelmesini amaçlamaktadırlar. Ülkemizde TUİK her yıl illere ait kültürel göstergeleri nispeten $\mathrm{AB}$ ve UNESCO'nın yapmış olduğu çalışmalara paralel olarak yayınlamaktadır.

Literatürde, kütüphane ve müze gibi kültürel unsurların VZA ile göreli etkinliklerinin değerlendirilmesi ile ilgili çalışmalara rastlamak mümkündür. Ancak, kültürel ve yaratıcı sektör gelişme kaydetmesine rağmen bir bölgenin veya ülkenin bütün olarak kültürel göstergelere dayalı göreli etkinliklerinin değerlendirildiği çalışmalar literatürde çok az yer almaktadır. Bu amaçla, 
çalışmada 81 ile ait TUIK' in (2012) yayınladığı kültürel göstergeler illerin VZA ile göreli etkinliklerinin değerlendirilmesinde kullanılmıştır. Toplam on girdi değişkeni ve altı çıktı değişkeninin kullanıldığı çalışmada çıktı yönlü CCR ve BCC modelleri kullanılmıştır.

Çıktı yönlü CCR modelinde 25 ilin, çıktı yönlü BCC modelinde ise 21 ilin etkin olmadığı belirlenmiştir. Her iki modelde de etkin olmayan iller Afyon, Erzincan, Maraş, Kars, Mardin ve Tokat'tır. Buna ilave olarak, analiz sonucunda 8 ilin ölçeğe göre azalan getiriye sahip olduğu 16 ilin ölçeğe göre artan getiriye sahip olduğu görülmüştür.

Ancak, çalışmada bulunan sonuçlar VZA'da kullanılan değişken kümesi ile sınırlıdır. Kültürel ve yaratıcı sektörün çıktılarını daha iyi açıklayabilen karşılaştırılabilir kültürel göstergelerin elde edilmesiyle birlikte, illerin göreli etkinliklerinin VZA ile değerlendirilmesi sonucunda hangi çıtı değişkenlerinin iyileştirilmesi gerektiği daha iyi anlaşılabilecektir. Böylelikle kültürel ve yaratıcı sektörler içerisinde illerin rekabet gücünün arttırılabilmesi yönünde politika yapıcılara daha yararlı bilgiler sunulabilecektir.

\section{KAYNAKLAR}

ATAN, M., ÖZGÜR, E., GÜLER, H. (2004), “ Çok Değişkenli İstatistiksel Analizler ve VZA ile İllerin gelişmişlik Düzeylerinin Karşılaştırılması”, Gazi Üniversitesi İktisadi ve İdari Bilimler Fakültesi Dergisi, 6/2, 25-42.

BANKER, R.D., COOPER, W.W., SEIFORD, L.M., THRALL, R.M., ZHU, J. (2004), "Returns to Scale in Different DEA Models", European Journal of Operational Research, Vol. 154, pp. 345-362.

BINA, V., CHANTEPIE, P., DEROIN, V., FRANK, G., KOMMEL, K., KOTÝNEK, J., ROBIN, P. (2012), ESSnet-Culture Final Report, Luxembourg: EU.

CHANG, H.-C., TING, C.-T., LEE, M.-H. (2012). Evaluating the efficiency of cultural and creative ability of cities in Taiwan. 17th International Conference on Cultural Economics in Kyoto. Kyoto.

CHARNES, A., COOPER, W.W., LEWIN, A.Y., SEIFORD, L. M. (1994), Data Envelopment Analysis: Theory, Methodology and Application, Kluwer Academic Publisher, Boston, USA.

CHARNES, A., COOPER, W.W., RHODES, E. (1978), "Measuring The Efficiency of Decision Making Units", European Journal of Operation Research, Vol. 2, pp. 429-444.

COELLI, T. (1996), “A Guide to DEAP Version 2.1: A Data Envelopment Analysis (Computer) Program", Centre for Efficiency and Productivity Analysis CEPA Working Paper, 08/1996.

COELLI, T.J., RAO D.S.P., O’DONNELL C.J., BATTESE G.E. (2005), An Introduction to Efficiency and Productivitiy Analysis, Springer, Second Edition, USA.

COOK, W.D., SEIFORD, L.M. (2009), "Data Envelopment Analysis (DEA) - Thirty Years On", European Journal of Operational Research, 192, pp. 1-17.

COOPER W.W., SEIFORD L.W., TONE K. (2000), Data Envelopment Analysis AComprehensive Text with Models, Application, References and DEA-Solver Software, Kluwer Academic Publishers, USA.

COOPER, W.W., SEIFORD, L.M., ZHU, J. (2011), "Handbook on Data Envelopment Analysis History, Models And Interpretations", International Series in Operations Research \& Management Science, Vol. 164, pp. 1-39.

COOPER; W.W., SHANLING, L., SEIFORD, L.M.; TONE, K.; THRALL, R.M.; ZHU, J. (2001), "Sensitivity And Stability Analysis in DEA: Some Recent Developments", Journal of Productivity Analysis, Vol. 15, N. 3. 
DYSON, R.G., ALLEN, R., CAMANHO, A.S., PODINOVSKI, V.V., SARRICO, C.S., SHALE, E.A. (2001), "Pitfalls And Protocols in DEA", European Journal of Operational Research, Vol: 132, I. 2, pp. 245-259.

ERDEM, R., ADIGÜZEL, O., KAYA, A. (2010), "Akademik Personelin Kurumlarına İlişkin Algıladıkları ve Tercih Ettikleri Örgüt Kültürü Tipleri", Erciyes Üniversitesi İktisadi ve İdari Bilimler Fakültesi Dergisi(36), 73-88.

ERTUĞRUL, İ., IŞIK, A.T. (2008), "İşletmelerin VZA İle Mali Tablolarına Dayalı Etkinlik Ölçümü: Metal Ana Sanayiinde Bir Uygulama”, Afyon Kocatepe Universitesi İ.İ.B.F. Dergisi, C. X, S. I.

FANCHON, P. (2003), "Variable Selection For Dynamic Measures of Efficiency in the Computer Industry", IAER, Vol. 9, No. 3, pp. 175-188.

FARRELL, M.J. (1957), "The Measurement of Productive Efficiency", Journal of The Royal Statistical Society, Vol. 120, No :3, S. 253-290.

GOLANY, B., ROLL, Y. (1989), "An Application Procedure For DEA”, Omega, International Journal of Management Science, Vol. 17, N. 3, pp. 237-250.

GOLDSTONE, L. (1999), Cultural statistics and poverty : Social dimensions of economic development and productivity : inequality and social performance, Santiago, Chile : United Nation.

GÖKGÖZ, F. (2009), Veri Zarflama Analizi Ve Finans Alanına Uygulanması, Ankara Üniversitesi Siyasal Bilgiler Fakültesi, Yayın No: 597, Ankara.

HILL, C. (2002), International Business: Competing in the Global Marketplace, New York: McGraw-Hill.

KARAHAN, A., ÖZGÜR, E. (2009). Hastanelerde Performans Yönetim Sistemi Ve Veri Zarflama Analizi. Ankara: Nobel Yayın Dağıtım.

KEA (2006). Economy of Culture in Europe, Brussels: European Affairs.

KIRAN, B. (2008), Kalkınmada Öncelikli İllerin Ekonomik Etkinliklerinin Veri Zarflama Analizi Yöntemi İle Değerlendirilmesi, Çukurova Üniversitesi Sosyal Bilimler Enstitüsü, Yayınlanmamış Yüksek Lisans Tezi.

KÖK, R., DELİKTAŞ, E. (2003), Endüstri İktisadında Verimlilik Ölçme Ve Strateji Geliştirme Teknikleri, Dokuz Eylül Üniversitesi İktisadi Ve İdari Bilimler Fakültesi Yayınları, İzmir.

KUAH, C.T., WONG, K.Y., BEHROUZI, F. (2010), “A Review On Data Envelopment Analysis (DEA)", 2010 Fourth Asia International Conference On Mathematical/Analytical Modelling And Computer Simulation.

KUMAR, S., GULATI, R. (2008), "An Examination of Technical, Pure Technical and Scale Efficiencies in Indian Public Sector Bank Using Data Envelopment Analysis", Eurasian Journal of Business and Econımics, 1 (2), 33-69.

MARCO-SERRANO, F. (2006). "Monitoring managerial efficiency in the performing arts: A regional theatres network perspective", Annals of Operations Research, 145(1), 167-181.

NORMAN M., STOKER, B. (1992), Data Envelopment Analysis The Assessment of Performance, John Wiley\&Sons, England.

ÖZDEMİR, N. (2009), "Kültür Ekonomisi ve Endüstrileri İle Kültürel Miras Yönetimi İlişkisi", Milli Folklor, 21(84).

RAY, S.C. (2004), Data Envelopment Analysis Theory and Techniques for Economics and Operations Research, Cambridge University Press, UK.

REICHMANN, G. (2004). Measuring University Library Efficiency. International Journal of Libraries and Information Services Using Data Envelopment Analysis, 54, 136-146.

RUGGIERO, J., BRETSCHNEIDER, S. (1998), "The Weighted Russell Measure of Technical Efficiency”, European Journal of Operational Research, 108,2, 438-451.

TAHERI, H., \& Ansari, S. (2013). Measuring the relative efficiency of cultural-historical museums in Tehran: DEA approach. Journal of Cultural Heritage, 14(5), 431-438.

TALLURI, S. (2000). Data Envelopment Analysis: Models and Extensions, Production/Operations Management, May, 8-11.

TARIM, A. (2001), Veri Zarflama Analizi: Matematiksel Tabanlı Göreli Etkinlik Ölçüm Yaklaşımı, Ankara: T.C. Sayıştay Başkanlığı, Araştırma Çeviri İnceleme Dizisi: 15. 
A. Okursoy \& D. Tezsürücü / Veri Zarflama Analizi ile Göreli Etkinliklerin Karşılaştırllması: Türkiye'deki Illerin Kültürel Göstergelerine İlişkin Bir Uygulama

TONE, K. (1996), "A Simple Characterization of Returns to Scale in DEA", Journal of The Operations Research Society of Japan, Vol. 39, No. 4.

TUIK (2012), Kültür İstatistikleri, Ankara: TUİK.

UN (2008), The Creative Economy Report, United Nations.

UNESCO (2001), Universal Declaration on Cultural Diversity, Paris: UNESCO.

UNESCO (2011, Februray), Culture forDevelopmentIndicator Suite: Analytical Framework,http://www.unesco.org/new/fileadmin/MULTIMEDIA/HQ/CLT/pdf/Conv200 5_CDindicators_Analytical_en.pdf adresinden alınmıştır (16.11.2013).

VINCOVA K.(2005), "Using DEA Models to Measure Efficiency”, BIATEC, Vol XIII, 8, 24-28.

VERN, T., KENNETH, D. (1985). The Cultural Environment of International Business, Cincinnati: South-Western Publishing.

WANG Qia, CUI Jin-Chuan, (2010), "A Resource Allocation Mode Based on DEA Models and Elasticity Analysis", The Ninth International Symposium on Operations Research and Its Applications (ISORA'10) Chengdu-Jiuzhaigou, China, August 19-23, 2010.

YUN, Y.B.; Nakayama H.; Tanıno, T. (2004), "Continuous Optimization A Generalized Model For Data Envelopment Analysis”, European Journal of Operational Research, Vol. 157.

ZHU Joe.( 2009), Quantitative Models for Performance Evaluation and Benchmarking Data Envelopment Analysis with Spreadsheets, Springer, Second Edition, USA. 